observations it was found that the immediate effect of the adrenergic drugs was similar.

To obtain a measure of the duration of effect of the different inhalants, serial assessments were continued for three and a half hours after each inhalant therapy on two groups of asthmatic subjects containing 12 subjects in each group. From these serial studies it was found that the inhalants gave distinct time-response curves.

The duration of isoprenaline was shortest; its action had been completely lost by 90 minutes. Adrenaline bitartrate and adrenaline hydrochloride combined with benzocaine were similar : a peak effect occurred at 15 minutes and was maintained up to 90 minutes, after which response gradually waned. Atropine methonitrate was found to have some immediate effect; the response reached a maximum at 90 minutes and was usually maintained throughout the three and a half hours of observation. The inhalation of isoprenaline in combination with atropine methonitrate showed substantial advantages over the other drugs tested. At 15 minutes the response was as good as the best isoprenaline response; it continued to improve for 120 minutes, after which it was maintained at this level during the three and a half hours of observation.

It is recommended that the frequency of administration of atropine methonitrate with or without adrenergic inhalants should be strictly controlled, especially in acute asthma.

We are indebted to the staff of the Department of Respiratory Physiology for carrying out the investigations described in this report, especially Mr. James Booth, S.R.N., Mr. Peter Wilkes, S.R.N., Mr. Norman Curnock, S.R.N., Mrs. Sheila Clarke, S.R.N., Mrs. K. Tattersfield, who prepared the graphs, and also Mrs. E. Turner and Mrs. E. C. Wright for the analyses.

\section{REFERENCES}

Altounyan, R. E. C. (1964). Thorax. In press.

Barger, G., and Dale, H. H. (1910). F. Physiol. (Lond.), $41,19$.

Chamberlain, D. A., Muir, D. C. F., and Kennedy, K. P. (1962). Lancet, 2,1019 .

Kennedy, M. C. S. (1953). Thorax, 8, 73.

Kennedy, M. Proc. Tuberc. Res. Counc., 48, 81.

and Jackson, S. L. O. (1963). Brit. med. F., 2, 1506.

Williams, D. A., and Leopold, J. G. (1959). Acta allerg. (Kbh.), 14, 83.

\title{
Use of Krypton-85 in the Study of Hypoxia in Porto-pulmonary Bilharziasis (Schistosomiasis)
}

\author{
H. A. ZAKY,* M.R.C.P.ED., T.D.D. ; A. R. EL-HENEIDY, $\dagger$ M.D. ; M. KHALIL
}

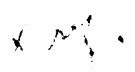

Brit. med. F., 1964, 1, 1021-1024

Porto-pulmonary bilharziasis often presents as hepatosplenomegaly and cor pulmonale (Zaky, 1952 ; Zaky et al., 1959). The haemodynamic changes in this disease have already been discussed (Foda, 1959; Zaky et al., 1962). We found that in about $10 \%$ of these cases hypoxia of less than $94 \%$ was present. This hypoxia could not be corrected by $100 \% \mathrm{O}_{2}$ inhalation.

When the alveolar $\mathrm{CO}_{2}$ tension was matched simultaneously against the arterial $\mathrm{CO}_{2}$ tension either at rest or on moderate exercise, a significant gradient was found between the alveolar $\mathrm{PCO}_{2}$ and the arterial $\mathrm{PCO}_{2}$, the latter being raised from 2 to $7 \mathrm{~mm}$. Hg. Studies of pulmonary function in these cases revealed almost normal findings (Ashba, 1959), particularly the minute alveolar ventilation and the helium-mixing time. These findings can only mean a veno-arterial admixture either inside the lung from pre-capillary pulmonary-artery/pulmonary-vein shunting or from the portal-vein blood to the pulmonary vein. In order to elucidate the above findings it was decided to carry out further investigations using the gas krypton-85.

\section{Materials and Methods}

Krypton-85 is a very interesting gas in that it is cleared by the alveoli to the extent of $95-99 \%$ in one circulation. We followed the method described by Fritts et al. (1960) to investigate the problem of a pre-capillary pulmonary-artery/ pulmonary-vein shunting. By this method a gas solute is

* Professor, Department of Chest Diseases, University of Alexandria, Egypt.

† Assistant Professor, Department of Chest Diseases, University of Alexandria, Egypt.

¥ Clinical Demonstrator, Department of Chest Diseases, University of Alezandria, Egypt. injected with a known quantity of a blue dye into the superior vena cava and both are recovered from the brachial artery within the period of one circulation. The concentration of dye is obtained from spectrophotometer readings, while the radioactivity is read on the scaler. The percentage of shunt is calculated from the formula:

${ }^{85} \mathrm{Kr}$ counts in integrated radial $\times$ conc. of dye injected mg. $/ 1$

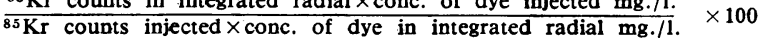

The pulmonary-artery concentrations after injection into the superior vena cava were calculated from the radiological size of the heart after the method of Hanson (1961), and the ratio of the right to the left cavities was considered to be $55-45 \%$. This gave the cardiac volume in which the dilution of superiorvena-cava injection could have taken place.

To investigate the problem of portal-vein/pulmonary-vein shunting, the same amount of krypton-85 was injected into the splenic pulp in bolus form; the bilharzial spleen lends itself admirably for the purpose as it is easily accessible and firm. We had no trouble while using this route in our cases apart from a moderate degree of pain after the injection. Samples were collected simultaneously from the pulmonary artery and the radial artery at approximately 10-second intervals for the first minute after the injection and at every 30 seconds for the next three to five minutes. The samples were then sealed in mica cuvettes and counted through an appropriate G.M. tube for five minutes.

\section{Results}

The first experiment, when the krypton-85 solute and the blue dye were injected into the superior vena cava, showed the 
absence of shunting between the pulmonary artery and the pulmonary vein (see Table). The shunt did not exceed $5.7 \%$ except in two cases (Nos. 1 and 5) in which it was $10 \%$.

Percentage of Pulmonary Artery/Pulmonary Vein Shunt After Superior Vena Cava Injection of Coomassie Blue Dye and Krypton-85

\begin{tabular}{|c|c|c|c|c|c|c|c|c|}
\hline \multirow{2}{*}{$\begin{array}{l}\text { Case } \\
\text { No. }\end{array}$} & \multicolumn{3}{|c|}{$\begin{array}{c}\text { Arterial } \mathrm{O}_{2} \\
\text { Saturation \% } \\
\end{array}$} & \multirow{2}{*}{$\begin{array}{c}\text { Conc. of } \\
\text { Dye in } \\
\text { Injected } \\
\text { Solution } \\
(\mathrm{g} . / 1 .)\end{array}$} & \multirow{2}{*}{$\begin{array}{c}\text { Conc. of } \\
\text { Dye in } \\
\text { Integrated } \\
\text { Radial } \\
\text { (mg./1.) }\end{array}$} & \multirow{2}{*}{$\begin{array}{l}\text { Conc. of } \\
\text { ss Kr in } \\
\text { Injected } \\
\text { Solution }\end{array}$} & \multirow{2}{*}{$\begin{array}{c}\text { Conc. of } \\
{ }^{85} \mathrm{Kr} \text { in } \\
\text { Integrated } \\
\text { Radial }\end{array}$} & \multirow{2}{*}{$\begin{array}{l}\text { Pulm.-art./ } \\
\text { Pulm.-vein } \\
\text { Shunt \% }\end{array}$} \\
\hline & Rest & $100 \%$ & $\begin{array}{c}\text { Exer- } \\
\text { cise }\end{array}$ & & & & & \\
\hline \multirow[t]{2}{*}{$\begin{array}{r}1 \\
2 \\
3 \\
4 \\
5 \\
6 \\
7 \\
8 \\
9 \\
10 \\
11 \\
12 \\
13 \\
14 \\
15\end{array}$} & $\begin{array}{l}88 \\
93 \\
93 \\
93 \\
90 \\
93 \\
94 \\
91 \\
94 \\
93 \\
93 \\
94 \\
94 \\
94 \\
96\end{array}$ & $\begin{array}{l}90 \\
94 \\
94 \\
94 \\
92 \\
93 \\
94 \\
92 \\
96 \\
93 \\
94 \\
94 \\
95 \\
96 \\
97\end{array}$ & $\begin{array}{l}88 \\
93 \\
92 \\
91 \\
90 \\
91 \\
94 \\
91 \\
93 \\
90 \\
93 \\
93 \\
93 \\
94 \\
96\end{array}$ & $\begin{array}{l}10 \\
10 \\
10 \\
13 \cdot 3 \\
10 \\
10 \\
10 \\
10 \\
10 \\
10 \\
10 \\
10 \\
10 \\
10 \\
10\end{array}$ & $\begin{array}{l}220 \\
190 \\
200 \\
300 \\
126 \\
200 \\
220 \\
200 \\
165 \\
200 \\
200 \\
205 \\
195 \\
185 \\
220\end{array}$ & $\begin{array}{l}90460 \\
253753 \\
78540 \\
249450 \\
321640 \\
251955 \\
371135 \\
574455 \\
467410 \\
446830 \\
416150 \\
535855 \\
462880 \\
315190 \\
232190\end{array}$ & $\begin{array}{r}211 \\
100 \\
51 \\
151 \\
487 \\
57 \\
470 \\
86 \\
165 \\
166 \\
167 \\
186 \\
267 \\
292 \\
220\end{array}$ & $\begin{array}{l}10 \\
2 \\
3 \cdot 2 \\
2 \cdot 6 \\
10 \\
1 \\
5 \cdot 7 \\
0 \cdot 77 \\
2 \\
1 \cdot 8 \\
2 \\
1 \cdot 7 \\
3 \\
4 \cdot 9 \\
3 \cdot 5\end{array}$ \\
\hline & \multicolumn{6}{|c|}{ Cases } & & \\
\hline $\begin{array}{l}16 \\
17 \\
18\end{array}$ & $\begin{array}{l}98 \\
98 \\
98\end{array}$ & $\begin{array}{l}100 \\
100 \\
100\end{array}$ & $\begin{array}{l}98 \\
98 \\
98\end{array}$ & $\begin{array}{l}10 \\
10 \\
10\end{array}$ & \begin{tabular}{|l|}
220 \\
350 \\
220
\end{tabular} & $\begin{array}{l}464915 \\
77710 \\
239565\end{array}$ & $\begin{array}{l}192 \\
139 \\
126\end{array}$ & $\begin{array}{l}1 \cdot 8 \\
5 \cdot 1 \\
2 \cdot 4\end{array}$ \\
\hline
\end{tabular}

When we examined the radial-artery samples after splenic injections we found that the degree of krypton concentration was almost equal to or even higher than that obtained in the same artery after injection into the superior vena cava (Fig. 1). When we considered the pulmonary-artery levels responsible for these radial-artery concentrations, we found that after splenic injection the pulmonary-artery concentrations were markedly lower than those after the superior vena cava injection. Another

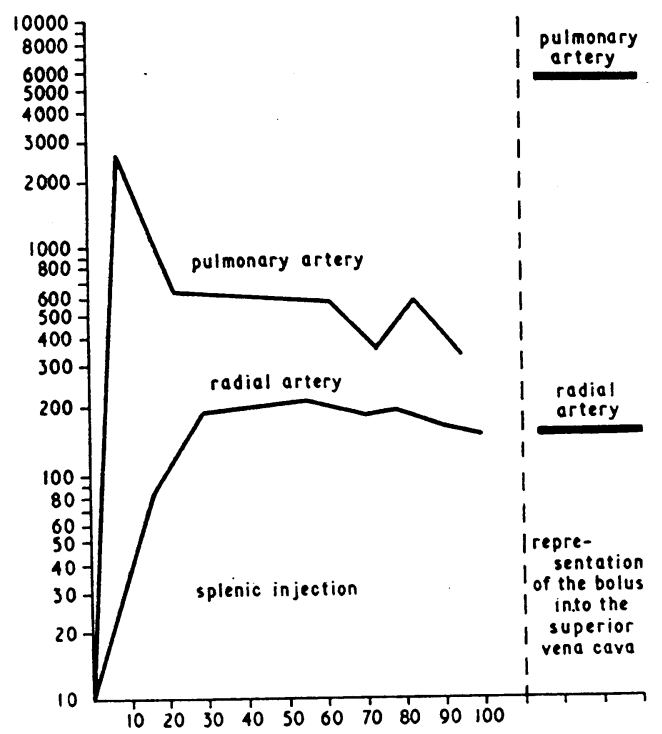

Fig. 1.-Curve of krypton-85 concentrations in pulmonary artery and radial artery after splenic injection. Comparative concentrations after superior vena cava injection are shown to the right of the curve.

finding was that radioactivity was present in the brachial artery in plateau form for about three minutes; then it started to decline (Fig. 1). In one case (Fig. 2) radioactivity was still present in the brachial artery 30 seconds after it had disappeared from the pulmonary artery. Another finding, in seven cases, was that the krypton concentrations in the pulmonary artery attained a high peak in the first 10 seconds after the splenic injection (Fig. 1).

\section{Discussion}

Of our 15 cases of hypoxia, 10 showed portal-vein/ pulmonary-vein shunting, two showed pulmonary-artery/ pulmonary-vein shunting, and three could not be explained by either route. Our data from the second experiment indicate that direct communications exist between the portal system and the pulmonary venous system, contributing to a veno-arterial admixture. The rapid high concentration in the pulmonary artery could not have arrived along the normal portal circulation, as this usually takes $25-30$ seconds. The primary peak presumably represents a short-circuit either to the superior vena cava via the vena azygos through the oesophageal (Fig. 4) and other intercostophrenic veins (Fig. 5) or short venae communicantes to the inferior vena cava.

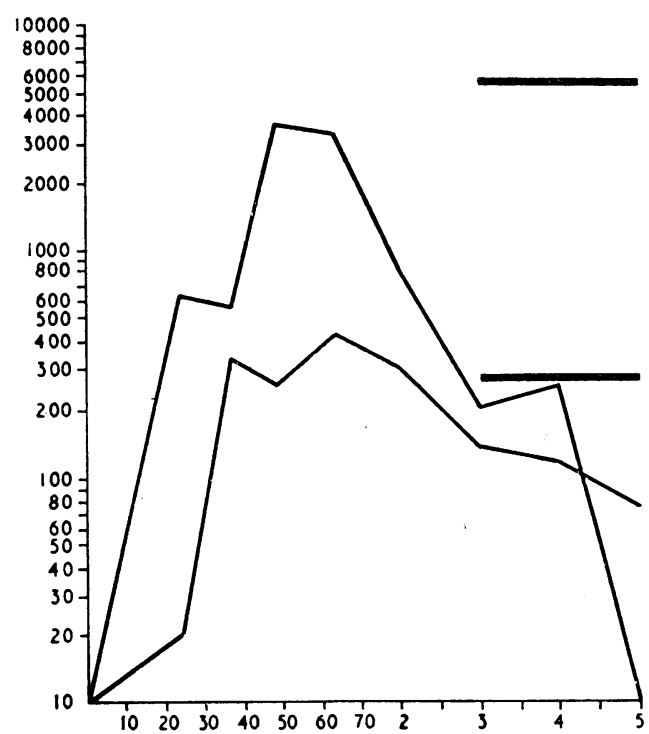

FIG. 2.-Curve showing presence of krypton-85 after splenic injection in radial artery 30 seconds after it disappeared from pulmonary artery.

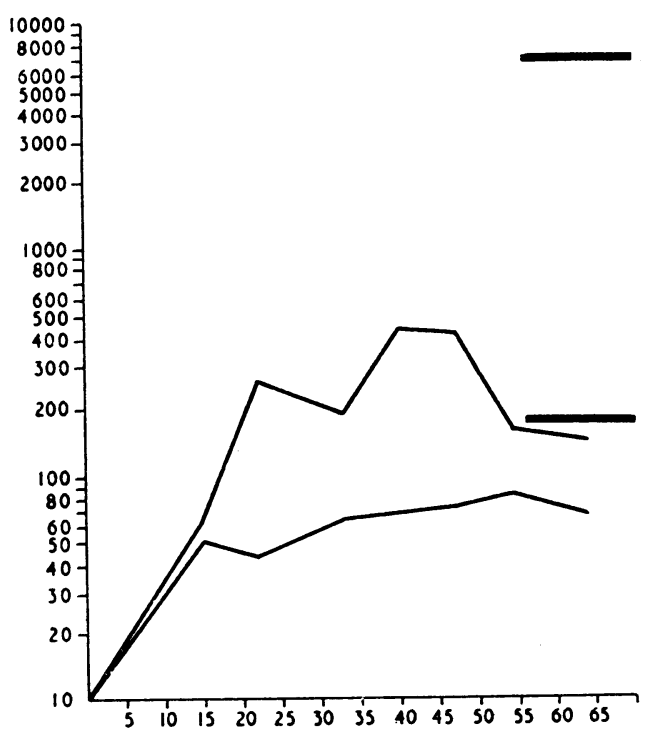

FIG. 3.-Curve showing multiple peaks in the pulmonary-artery samples after splenic injection.

The splenic pressure was high in the cases that showed the primary peak in the pulmonary-artery concentration, the pressure ranging from 25 to $32 \mathrm{~mm}$. $\mathrm{Hg}$. The fact that krypton-85 may stay as long as five minutes suggests that the degree of pooling in the overdistended portal system is enormous.

In one case (Fig. 3) the multiple peaks in the pulmonaryartery samples suggested various short-circuits of different lengths, velocities, and magnitudes at different levels.

As was mentioned earlier, our bilharzial cirrhotic cases could not be fully saturated by inhalation of $100 \%$ oxygen. On inhalation of $100 \% \mathrm{O}_{2}$, normally the blood plasma is capable 
of carrying a further $1.8 \mathrm{vol} \%$ in solution at $600 \mathrm{~mm}$. $\mathrm{Hg}$ of alveolar-oxygen tension. It is presumed that the oxygen saturation can be raised a further $8 \%$ or so provided all the cardiac output flows over the alveoli. In bilharzial cirrhosis it rises

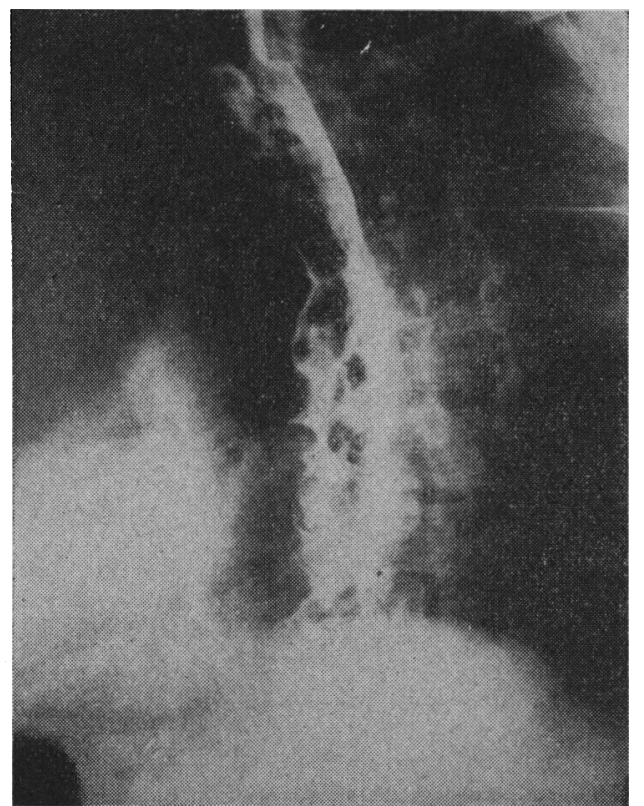

FIG. 4.-X-ray film of oesophagus with barium showing extensive varicose veins in a case of portopulmonary bilharziasis. (By courtesy of Dr. Fadali.)

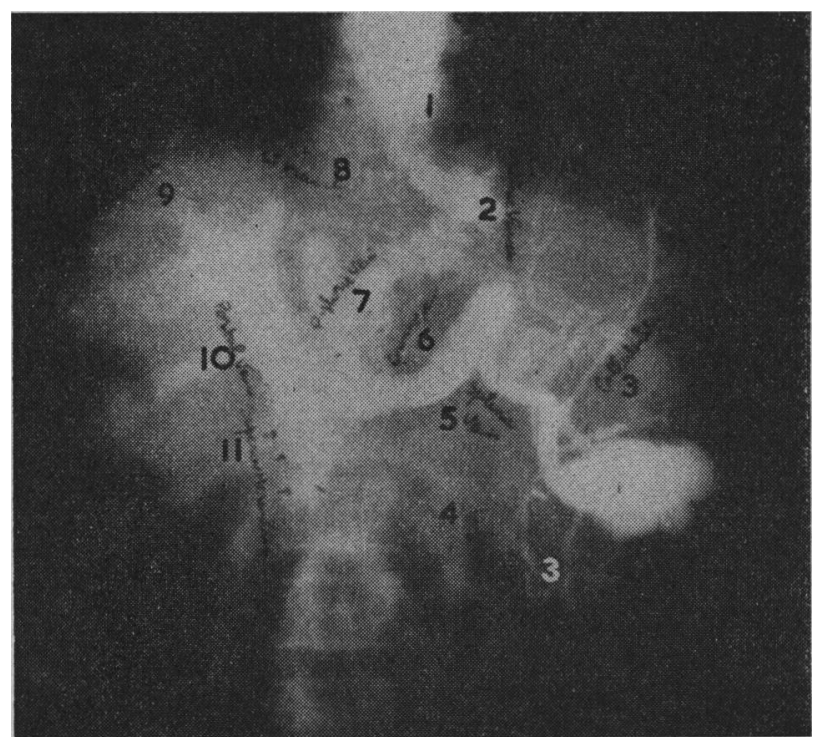

FIG. 5.- Spleno-portography showing marked intercostophrenic collaterals. 1, Oesophageal varix. 2, Gastric varices. 3, Collaterals. 4, Inferfor mesenteric. 5, Splenic vein. 6, Coronary veins. 7, Pyloric vein. 8, Left portal branch. 9, Right portal branch. 10, Portal vein. 11, Superior mesenteric. (By courtesy of Dr. Salab.)

only by $2-3 \%$. This discrepancy suggests that the problem cannot have a simple shunt explanation. The question has been raised by other writers (Keys and Snell, 1938 ; Schlant et al., 1962) that the red cells may have a defective ability for immediate oxygen uptake. However, when the hypoxic blood of our patients was exposed to ordinary atmospheric oxygen tension (105 $\mathrm{mm} . \mathrm{Hg}$ ) in vitro with no time limit, the blood registered a normal $100 \%$ saturation. Whatever the factors may be which are responsible for the desaturation, they only operate intra vitam.

Atropine was injected in three cases intravenously in the dose of $1 \mathrm{mg}$., but it had no influence on the arterial hypoxia up to five minutes. It may be presumed, therefore, that neither acetylcholine nor acetylcholine esterase (which is believed to be low (El-Hawari, 1958) in cirrhosis of liver) is an important factor. Either some unknown substance exists which operates only inside the body and prevents the red cell from oxygen saturation in the brief interval it crosses the alveoli, in addition to the portal-vein/pulmonary-vein shunting, or the latter really attains a much higher magnitude than is at present conceived.

In Fig. 6 we tried to sum up the various shunts that occur in porto-pulmonary bilharziasis. It incorporates splenic shunts (Zaki et al., 1962), oesophageal and other intercostophrenic veins to the vena azygos, or short venae communicantes to the inferior vena cava ; all these contribute to a diastolic overloading

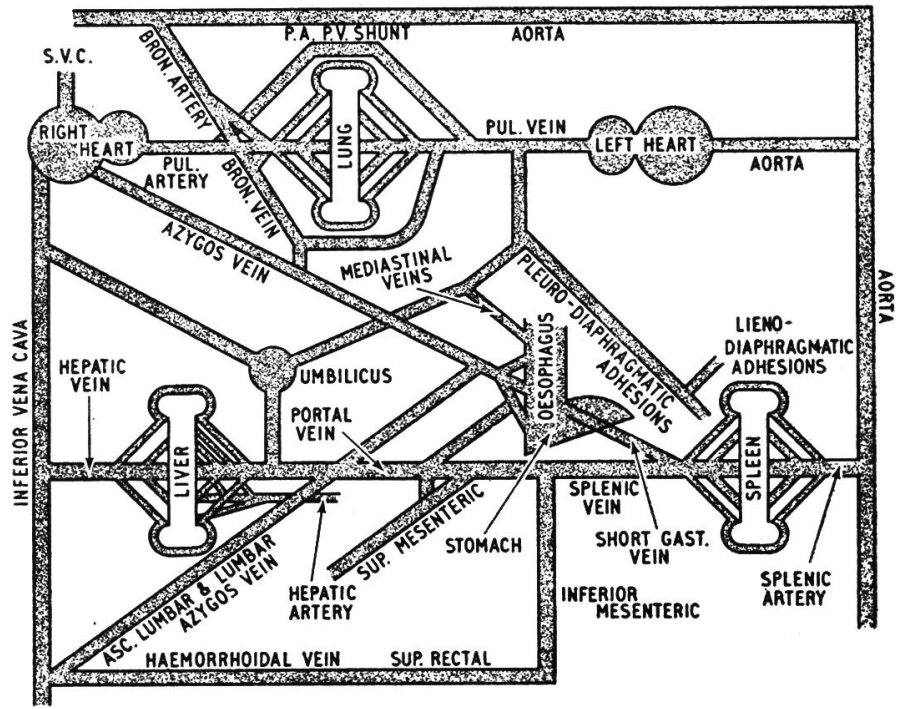

FIG. 6.-Diagram showing the various haemodynamic shunts in portopulmonary bilharziasis.

of the right ventricle. Bronchopulmonary shunts increase the systolic work of the right ventricle. Repetitive showers of schistosoma ova that lodge in the branches of the pulmonary artery create further occlusive angiitis, which increases the total pulmonary arteriolar resistance. The large size of the pulmonary arteries is therefore due to an increase in flow, pressure, and resistance in competition with each other.

The hypoxia in most cases is contributed to by portal-vein/ pulmonary-vein shunting. Few cases have precapillary pulmonary-artery/pulmonary-vein shunting, but full explanation of the remaining factors, particularly the problem of bronchialvein/pulmonary-vein shunting, still awaits further investigation.

\section{Summary}

Hypoxia of a degree less than $94 \%$ appears in portopulmonary bilharziasis in about $10 \%$ of cases.

Fifteen cases have been studied, using the gas krypton-85, to elucidate the presence of veno-arterial admixture, either in the lungs btween the pulmonary artery and the pulmonary vein or in the portal circulation between the portal vein and the pulmonary vein.

Injection of krypton-85 into the superior vena cava with a dye and the recovery of both from the radial artery in one circulation revealed the absence of shunts in the lungs except in two cases.

Injection of krypton-85 into the spleen and taking simultaneous samples from the pulmonary artery and the radial artery revealed the presence of shunts between the portal vein and the pulmonary vein.

In seven cases high concentrations of krypton-85 in the pulmonary artery within 10 seconds indicated a short-circuit from the portal circulation to the superior vena cava. This 
presumably takes place via the vena azygos through oesophageal and other intercostophrenic veins or short venae communicantes to the inferior vena cava.

The krypton injected into the spleen as a bolus could be recovered from the radial artery as late as five minutes afterwards, indicating marked overdistension and retardation in the portal pool.

A summary of the various haemodynamic shunts in portopulmonary bilharziasis is presented in Fig. 6 .

We are grateful to the National Research Council and Dr. S. Hashish, whose active co-operation in the nuclear physics department made the work with krypton possible.

\section{REFERENCES}

Ashba, J. (1959). Thesis, University of Alexandria.

El-Hawari (1958). Gaz. Kasr-El-Aini Fac. Med., 24, 234.

Foda, M. T. (1959). Thesis, University of Alexandria.

Fritts, H. W., Hardewig, A., Rochester, D. F., Durand, J., and Cournand, A. (1960). F. clin. Invest., 39, 1841.

Hanson, J. S. (1961). f. Amer. med. Ass., 176, 16.

Keys, A., and Snell, A. M. (1938). 7. clin. Invest., 17, 59.

Schlant, R. C., Tsagaris, T. J., Robertson, R. J., Winter, T. S., and Edwards, F. K. (1962). Amer. Heart f., 64, 512.

Zaky, H. A. (1952). Dis. Chest, 21, 194.

- El-Heneidy, A. R., and Foda, M. T. (1962). Brit. med. F., 1, 367. - Tawfick, I. M., Gemei, Y., and Khadr, A. A. (1959): Dis. Chest, 36, 164.

\title{
Spontaneous Intraperitoneal Haemorrhage During Pregnancy : Report of Three Cases
}

\author{
W. A. HANNA,* M.B., F.R.C.S.ED.; T. J. M. MYLES, † M.D., M.R.C.o.G.
}

Brit. med. F., 1964, 1, 1024-1026

Spontaneous intraperitoneal haemorrhage during pregnancy or the puerperium, although relatively rare, may be due to a variety of causes and may originate from any intra-abdominal artery or vein, or a blood-filled viscus. Rupture of a splenicartery aneurysm is perhaps the best-known source of such bleeding, but the basic features and principles of management are similar whether the site of bleeding is in the upper or the lower abdomen. It is evident from the literature that there is still often a considerable delay in diagnosis, which adversely affects the results of treatment. Three cases treated in Banbridge Hospital and Lurgan and Portadown Hospital, and reported below, illustrate different sources of haemorrhage. Obstetrical cases in these two neighbouring hospitals are under the overall care of the one consultant, although in Banbridge Hospital general practitioners look after their own normal cases. Both hospitals have a combined emergency surgical duty rota.

\section{Case 1}

A married woman aged 27 , gravida-2, para-0, was admitted to Banbridge Hospital on 1 April 1961 when 23 weeks pregnant. Her first pregnancy in 1960 had ended in abortion at 10 weeks. She had awakened from sleep with severe abdominal pain and had called her doctor, who found her blood-pressure to be $90 / 50 \mathrm{~mm}$. Hg but without tachycardia. There was generalized abdominal tenderness and the uterus corresponded in size to a 22 -weeks pregnancy. The foetal heart could be heard. Immediate admission to hospital was arranged.

On arrival at hospital the patient's colour was good, the pulse rate 100 , and the systolic pressure had risen to $120 \mathrm{~mm}$. $\mathrm{Hg}$. The uterine fundus was at the level of the umbilicus and the foetal heart was audible. There was generalized abdominal tenderness, maximum in both iliac fossae, with guarding and rebound tenderness. A provisional diagnosis of intraperitoneal bleeding, possibly from a splenic-artery aneurysm, was made, blood transfusion was started and arrangements were made for laparotomy.

At operation the abdomen was entered through a left paramedian incision and the peritoneal cavity was found to contain 2 pints $(1,140$

* Lately Senior Surgical Registrar, Banbridge Hospital, Northern Ireland. At present Senior Tutor, Department of Surgery, Queen's University, Belfast.

† Consultant Obstetrician and Gynaecologist, North Armagh, Banbridge and Dromore Hospital Groups, Northern Ireland. ml.) of blood and blood clot. The site of bleeding was a vein on the anterior surface of the uterus and a small tear was present in the peritoneum overlying the bleeding-point. The bleeding was controlled by suturing the area with interrupted catgut sutures over gel foam soaked in thrombin. Blood and blood clot were cleared from the peritoneal cavity and the abdomen was then closed in layers without drainage. A total of 2 pints $(1,140 \mathrm{ml}$.) of blood was given before and during operation and the patient's post-operative condition was satisfactory. Recovery afterwards was uneventful and she was discharged home on 15 April.

The remainder of her pregnancy was normal, and on 29 June she had a normal delivery of a living child weighing $7 \mathrm{lb} .5 \mathrm{oz}$. $(3,315$ g.). Subsequent inquiry from another hospital in which she had been curetted after her previous abortion showed that there had been no complications at that time and nothing to suggest perforation of the uterus at operation. No history of trauma during the present pregnancy could be obtained, and it must be presumed that the intraperitoneal bleeding was spontaneous.

\section{Case 2}

A married woman aged 38, gravida-6, para-5, collapsed at home with sudden severe left-sided abdominal pain on 26 June 1961 . She was then 10 days past her expected date of confinement and had been feeling well until one week previously, when she had developed a cough and slight continuous pain in the left loin. Her previous pregnancies and labours had been normal.

The obstetric flying squad was called, and on arrival found the patient to be severely shocked, pale, cold, and cyanosed, with stertorous breathing. The pulse was thready, rate 140, and the systolic pressure was $65 \mathrm{~mm}$. Hg. Crepitations were heard at both lung bases. The uterus corresponded in size to a term pregnancy and was contracting. The presentation was vertex with the head engaged, and the foetal heart could be heard. There was no tenderness over the uterus, but tenderness was marked in the left flank. There was no revealed vaginal bleeding.

Blood transfusion was started immediately and 2 pints $(1,140 \mathrm{ml}$.) of blood was given rapidly, after which the blood-pressure rose to $115 / 75 \mathrm{~mm}$. Hg and the pulse rate dropped to 120 . A third pint $(570 \mathrm{ml}$.$) of blood was begun and the patient was transferred to the$ Lurgan and Portadown Hospital, 7 miles $(11 \mathrm{~km}$.) distant. During the journey the blood-pressure started to fall again and on admission to hospital the systolic pressure was $75 \mathrm{~mm}$. $\mathrm{Hg}$. Further blood was transfused and the patient's condition improved. By this time the foetal heart was no longer audible. 